\title{
A Study On Outcome of Epidural Analgesia for Painless Labour
}

\author{
Dr. Asha Kumari ${ }^{*}$, Dr. Renu Rohatgii* ${ }^{*}$ Dr. Ankita Mishra*** \\ *Postgraduate, Department of Obstetrics \& Gynecology, Nalanda Medical College and Hospital, Patna.(Corresponding author \\ **Professor,Head of Deparment, Department of Obstetrics \& Gynecology, Nalanda Medical College and Hospital, Patna. \\ **** Postgraduate student, Department of Obstetrics and Gynecology, Nalanda Medical College \& Hospital, Patna.
}

DOI: 10.29322/IJSRP.10.03.2020.p9917

http://dx.doi.org/10.29322/IJSRP.10.03.2020.p9917

\begin{abstract}
OBJECTIVE:- To assess the quality of pain relief , obstetrical outcome, effect on rate of cesarean section \& instrumental delivery.

MATERIAL \& METHOD:- 100 patient in labour were selected based on inclusion criteria, informed consent taken prior to study. Epidural analgesia given and we retrieved the course of labour \& delivery and management of epidural analgesia done.

RESULT:- A total 100 patients, 94 patients was having adequate pain relief, 38 normal vaginal delivery, 47 instrumental delivery, 15 cesarean section.

CONCLUSION:-Epidural analgesia for painless labour is safe \& effective method with very less side effect, no increase in rate of CD \&IVD or prolongation of labour.
\end{abstract}

\section{INTRODUCTION}

L abour pain is probably the most painful event in womens life ${ }^{1}$. It has been well established \& stated best by ACOG and ASA, that in absence of medical contraindication maternal request is a sufficient medical indication for pain relief during labour. By the present consensus neuraxial analgesia technique including Epidural, spinal, and combined spinal epidural approaches are the most effective \& least depressant treatment for labour pain. Previous studies disclosed the increase incidence of cesarean deliveries rate in parturient who received epidural in early stage of labour. However recent randomized control trial showed no difference in the incidence of cesarean delivery.The ACOG committee opinion in 2006, recommended that" The fear of unnecessary cesaerean delivery should not influence the method of pain relief that women wish to choose during labor.

Study is carried out in NALANDA MEDICAL COLLEGE \&HOSPITAL, Patna, Bihar. In this study effect of epidural analgesia on mode of delivery,course of labour,\& outcome of pregnancy done in detail.

\section{MATERIAL AND METHOD}

This study was approved by ethical committee of our hospital.It was prospective study on patient attending the emergency in Department of obstetric \& gynaecology at nalanda medical college $\&$ hospital, patna from dec 18 to dec 19 .

Patients were educated \& counseled about labour analgesia. Epidural analgesia was initiated at parturient request. Informed consent taken prior to study, total 100 patients in labour were selected based on inclusion criteria.

Prior to procedure, vitals(BP,Pulse), fetal heart rate, CTG(admission CTG), cervical dilatation is noted as baseline data.

Skin is infiltrated with $1 \%$ xylocaine, an epidural catheter was inserted via L3- L4 or L4- L5 intervertebral space through a 16 or 18 Gauge touhy needle in place. The LOR(Loss of resistence) technique was used to identify the epidural space.The catheter was threaded 4-7 cm cephalad through the needle. Then test dose of $3 \mathrm{ml} 1 \%$ xylocaine was given to rule out intravascular or intrathecal catherization before the catheter was secured. Then bolus dose of $10 \mathrm{ml}$ of $0.0625 \%$ of Bupivacaine with $20 \mathrm{mcg}$ of fentanyl, intermittent dose is given when patient complain of pain. The visual analog scale is used to assess the degree of pain $\&$ When to give intermittent dose. During study all parameter \&Obstetrical outcome are documented in detail.

\section{RESULT}

There was total 100 patients, to whom epidural was given, out of 100 patients 38 delivered by assisted vaginal delivery, 47 had instrumental delivery, cesarean section in 15 patients. From this study we found there is no incidence of rate of cesarean section but rate of instrumental delivery markedly increased. We also found that, result are not affected by timing of epidural.

TABLE-1 Distribution of cases according to age group

\begin{tabular}{|c|c|c|}
\hline AGE IN YRS & NO. OF CASES & PERCENTAGE \\
\hline$<20 \mathrm{Yr}$ & 12 & $12 \%$ \\
\hline $20-25 \mathrm{Yr}$ & 70 & $70 \%$ \\
\hline
\end{tabular}




\begin{tabular}{|l|c|c|}
\hline $26-30 \mathrm{Yr}$ & 14 & $14 \%$ \\
\hline$>30 \mathrm{Yr}$ & 4 & $4 \%$ \\
\hline & & \\
\hline
\end{tabular}

TABLE-2 Distribution of cases according to Gravida

\begin{tabular}{|c|c|c|}
\hline GRAVIDA & NO. OF CASES & PERCENTAGE \\
\hline G1 & 74 & $74 \%$ \\
\hline G2 & 22 & $22 \%$ \\
\hline G3-G4 & 04 & $04 \%$ \\
\hline
\end{tabular}

TABLE-3 Distribution of cases according to Mode of delivery

\begin{tabular}{|l|c|c|}
\hline MODE OF DELIVERY & NO. OF CASES & PERCENTAGE \\
\hline ASSISTED VAGINAL DELIVERY & 38 & $38 \%$ \\
\hline INSTRUMENTAL DELIVERY & 47 & $47 \%$ \\
\hline CESAREAN SECTION & 15 & $15 \%$ \\
\hline
\end{tabular}

TABLE-4 DISTRIBUTION OF CASES ACCORDING TO SUCCESS OF EPIDURAL FOR PAIN RELIEF

\begin{tabular}{|c|c|c|}
\hline SUCCESS & NO. OF CASES & PERCENTAGE \\
\hline SUCCESSFUL & 94 & $94 \%$ \\
\hline UNSUCCESSSFUL & 6 & $6 \%$ \\
\hline
\end{tabular}

TABLE-5 DISTRIBUTION OF CASES ACCORDING TO MATERNAL SIDE EFFECT

\begin{tabular}{|l|c|c|}
\hline SIDE EFFECT & NO OF CASES & PERCENTAGE \\
\hline NAUSEA, VOMITING & 60 & $60 \%$ \\
\hline HEADACHE & 20 & $20 \%$ \\
\hline MOTOR BLOCK & 12 & $12 \%$ \\
\hline PRURITUS & 08 & $08 \%$ \\
\hline
\end{tabular}

\section{DISCUSSION}

There was three major finding in this study, first about rate of cesarean section which doesn't increases, secondly there was mild prolongation of $2^{\text {nd }}$ stage of labor which is not significant, thirdly increase in rate of instrumental delivery.

Severity of labor pain is graded highest on pain scale, early labor pain is visceral(T10-L1), and late is somatic(S2-S4).There is multiple way available for relief of labor pain. But epidural is best. However, women who uses this form of pain relief are at increased risk of instrumental delivery, our this result matches with study which was done by Somvah.et.al

The worry about increasing CD rate due to epidural, but we found no significant increase in rate, same view was by shared by Elizabeth MC Grandy . et. al study.

Epidural analgesia can be given at any time at request of patient, it doesn't matter what is the cervical dilatation. Timing of epidural does not effect the mode of delivery \& no adverse effect on neonatal outcome, same result was obtained by Wong.et.al .

\section{CONCLUSION}

Epidural analgesia for painless labour is simple, safe \& effective technique. Controversies regarding like rate of $\mathrm{CD}$ are irrelevant.

There is no increase in rate of instrumental delivery

Epidural analgesia is better choice rather than to bear labor pain.

\section{ABBREVIATION}

CD- cesarean delivery, RCT- Randomized controlled trial,IVD- Instrumental vaginal delivery.

\section{REFERENCES}

[1] 1.ACOG Committee opinion no.295. Pain relief during labor. Obstet Gynecol 2004;104:213. 
[2] 2.Hawkins JL, gibbs CP, Orleans M, Martin-Salvaj G, Beaty B. Obstetric anesthesia work force survey, 1981 versus 1992,Anesthesiology 1997;87:135-43.

[3] 3.Thorp JA. Epidural analgesia for labour: effect on the cesarean birth rate. Clin Obstet Gynecol 1998;41:449-60.

[4] 4.Lee HL, Lo LM, Chou CC, Chiang TY, Chuah EC. Timing of initiating epidural analgesia and mode of delivery in nulliparous: A retrospective experience using ropivacaine. Chang Gung Med J 2008;31:395-401.

[5] 5.Wassen MM,Zuijlen J,Roumen FJ, Smits LJ, Marcus MA, Nijhuis JG. Early versus late epidural analgesia and risk of instrumental delivery in nulliparous women:a systematic review. BJOG 2011;118:655-61.

[6] 6.Chestnut DH, McGrath JM, Vincent Jr RD, penning DH, Choi WW, Bates $\mathrm{JN}$, et al. Does early administration of epidural analgesia affect obstetric outcome in nulliparous women who are in spontaneous labor? Anesthesiology 1994;80:1201-8.

[7] 7.American College of Obstetricians and Gynecologists committee onObstetric Practice. ACOG Committee Opinion No.339: analgesia and cesarean delivery rates. Obstet Gynecol 2006;107:1487-8.
[8] 8."Epidural for pain relief in labour " by Authors: Anim- Somvah M, Smyth RMD, Jones L Elsevier Published: 7 December 2011.

[9] 9.Epidural analgesia in labour by Elizabeth MC Grandy Oxford Journals Medicine \& Health BJA : CEACCP Volume 4, Issue 4 Pp. 114-117.

\section{AUTHORS}

First Author - Dr. Asha kumari, Postgraduate, Department of Obstetrics \& Gynecology, Nalanda Medical College and Hospital , Patna.(Corresponding author

Second Author - Dr. Renu Rohatgi, Professor,Head of Deparment, Department of Obstetrics \& Gynecology, Nalanda Medical College and Hospital, Patna.

Third Author - Dr. Ankita Mishra, Postgraduate student, Department of Obstetrics and Gynecology, Nalanda Medical College \& Hospital, Patna. 